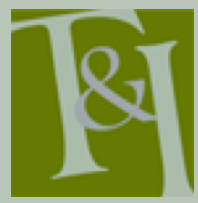

The International Journal for Translation \& In erpreting Research trans-int.org

\section{Medical terminology rendition techniques employed by paraprofessional Chin-Hakha $<>$ English interpreters}

\author{
Salai Biak Za Lian Ching \\ Deakin University, Australia \\ liankyi@gmail.com
}

DOI: 10.12807/ti.109202.2017.a03

\begin{abstract}
This paper presents a study of the techniques employed by paraprofessional Chin-Hakha community interpreters when interpreting in a medical setting. Data was collected through a simulated dialogue in which participants were asked to interpret consecutively. Participants were then interviewed about their decision-making processes in formulating renditions of a number of medical terms. Lexical analysis found that Chin-Hakha interpreters produce interpretations of medical terminology according to certain observable patterned constructions. Overall, this study confirms the community interpreter's role as a 'negotiator' of language, where interpreters negotiate the intended meaning of specialised terminology by using their own 'storeroom' of linguistic skills and medical knowledge so as to be successful in rendering medical conversations.
\end{abstract}

Keywords: Chin-Hakha language, community interpreter, latitude, medical interpreting, terminological/ lexical challenges

\section{Introduction}

One of the most remarkable developments in interpreting studies since the mid-1990s has been the emergence of community interpreting as an increasingly significant field of professional practice and academic research (Pöchhacker \& Shlesinger, 2007, p. 1). Community interpreting is a form of practice defined as interpreting undertaken in public service and welfare settings, mostly in consecutive (dialogue) mode. The health care context is particularly challenging because of the differences that typically exist in the language competency, linguistic practise, and socioeconomic status of service providers and the members of the public who use such services. However, there are few medical interpreting studies that address lexical challenges, apart from Scaioli (2000) and McCabe et al. (2003). Lexical challenges are a major concern for legal interpreting (Morris, 1995; Hayes, 2009) and conference interpreting (Dam, 2000), but rarely appear in community interpreting studies. There are also no existing studies that address the challenges faced by community interpreters from Myanmar, in particular, Chin-Hakha language interpreters.

Translation \& Interpreting Vol 9 No 2 (2017) 
This study focuses on paraprofessional Chin-Hakha community interpreters working in Melbourne, Australia. Chin-Hakha is a language spoken widely in the Chin State of Myanmar and in Chin diasporas around the world ${ }^{\mathrm{i}}$. Good quality interpreting services are important for Chin people living in the West as many of them are not familiar with Western medicine or healthcare institutions, and therefore are a relatively vulnerable population in terms of capacity to have their medical needs met.

\section{Lexical challenges in medical interpreting}

Medical interpreting often involves rendering complex terms developed specifically to describe clinically identifiable conditions in languages that do not have such terms in ways that can be understood by the average speaker. This represents a particular challenge, especially when the target language in question does not have a traditional conceptualization of internal medicine. Working with the Navajo language, Scaioli (2000) analysed the interpretation of medical terminology using a questionnaire to evaluate the practice of several Navajo medical interpreters working at a Native American Health Service. She asked respondents for their interpretation of technical terms such as 'glycosylated haemoglobin' and 'carbohydrates'. For Navajo interpreters, this required a lengthy explanation and clarification. Scaioli found that Navajo interpreters explained the term by starting with information about blood tests: from the "observable fact that blood is red...[they] described glucose as attached to these red blood cells" (p. 119). When the explanation and clarification were complete, 'glycosylated haemoglobin' was finally interpreted as 'the measurement of the breakdown of glucose' and its literal rendition in English became 'energy that comes from the food juices' and 'energy from the food in the blood system from the past three months' (p. 120). The technical term 'carbohydrates' has no equivalent in Navajo, which resulted in the interpreters "first [providing] a non-specialized rendition in English before [rendering] the concept [and meaning] into Navajo" (p. 121). Scaioli thus concluded that linguistic equivalency is not always achievable nor even desirable. Since the Navajo language has grammatical structures that diverge significantly from those of English (p. 118), Scaioli argued that "word for word [interpretation] is useless and deceptive since it does not convey the adequate meaning of such complex medical term[inology], but only their structural linguistic forms that have no meaning in the Navajo language" (p. 121). Scaioli's work shows that meaning-based approaches to linguistic equivalence need to account for significant latitude being possible, even desirable, when specialised terminology in expert fields of other cultures (such as Western medicine) are not necessarily part of the target language and society.

McCabe et al. (2003) also conducted similar research on the Navajo language. However, they restricted their research to the medical term 'diabetes', which is translated to 'sugar illness' in the Navajo language. Although translators and interpreters made clear and acceptable renditions into the Navajo language, they also used stories to explain the meaning of the

\footnotetext{
i Chin people from Myanmar have resettled in the USA, Canada, Australia, New Zealand, Malaysia, India, Norway, and Denmark.
} 
term. The researchers found that the use of stories is a linguistically and culturally appropriate interpretation strategy for Navajo interpreters. They also found that interpreting the medical term diabetes and its associated concepts (such as insulin) into Navajo was very complex. They emphasised that "being able to speak clients' native language alone is not sufficient" (p. 56); in order to achieve meaningful interpretation, attention must be paid to cultural factors, regional language differences, and the possibility of a lack of word-for-word (literal) interpretation / translation in explaining and interpreting diabetes management in an appropriate cultural context.

A similar set of issues has been recognized in interpreting in other contexts. Dam (2000) examined a small-scale corpus of simultaneous conference interpretations (interpreting Spanish speeches into Danish). He examined the gap between form-based and meaning-based interpreting. Formbased interpreting is described as more or less direct transmission of the source language to corresponding structures in the target language. Meaningbased interpreting happens when the interpreter detaches him/herself from the source language form and produces the target language only on the basis of the conceptual content of the original utterance. Dam (2000) concluded that interpreters used both form-based and meaning-based interpreting, but that the form-based strategy is associated with less difficult source texts, whereas the meaning-based strategy is linked with more difficult texts (p. 52).

Morris (1995) addressed the issue of interpreter latitude in court (legal) interpreting, specifically problems associated with the interpretation or translation of ambiguous judicial terms, such as 'character reference', 'certificate of good conduct' and 'criminal record', and their counterparts in other languages (French, German and Dutch). Because interpreters act in a space between two different languages and different social contexts, and the nature of legal terminology produces many challenges in judicial interpreting, Morris concluded that a 'pragmatic approach' worked in legal interpreting, where interpreters are allowed to "exercise the necessary latitude in dealing with the inherent difficulties" in their interpreting (p. 42). Exercising latitude meant "providing an explanation of the relevant procedure in order to site the document within its cultural context" (p. 37). Similarly, Jacobsen (2002) has argued that "despite official requirements for verbatim [word for word] translation, some court interpreters are prepared to exercise latitude and modify originals in order to convey their perception of speaker meaning" (cited in Morris 1995, p. 31).

In each of these studies, the issue of latitude, the degree to which an interpreter diverges from the form and content of the source material, was central to an understanding of interpreter strategies. Latitude then also refers to the interpreter "be[ing] given the time to act and decide for him/herself" (Orlando 2010, p. 54). Morris (1995) elaborated on this concept through a consideration of problems associated with the interpretation or translation of ambiguous judicial terms. She argued that the court interpreter should be given a wider degree of latitude when it comes to interpreting more complex legal terminology. The present study uses Hatim \& Mason's (1999) concept of latitude as a framework for data analysis. These authors note that the degree of latitude that should be used by interpreters has long been an issue, and many scholars believe that equivalence can best be achieved through literal interpretation when it allows for pragmatic and referential equivalence (see, for example, Newmark, 1988). 
For some languages, however, literal translation is simply not possible in certain settings because of the constraints posed by the target language relative to the source language material that needs to be interpreted. This is the case when working with the Chin-Hakha language in the medical context as part of the community interpreting services available in Australia. In Australia, community interpreters work with medical, legal, housing, employment, and other related agencies that deal with immigrant and refugee issues. This includes medical settings such as public and private hospitals, healthcare centres, and early childhood centres. In hospitals, each department provides a variety of medical services to culturally diverse non-English-speaking patients, many of whom need interpreting services. Napier, Goswell \& McKee (2010) note that the interpreting task in medical institutions is "diverse and unpredictable" in a "high stakes setting" (pp. 111-112). This diversity derives not just from the medical specialisation but also the kind of appointment undertaken (intake, consultation, or procedural).

For Chin-Hakha community interpreters, the main challenge of interpreting in a medical setting is that some medical terms do not exist or do not have any lexical equivalent in Chin-Hakha. Western medical terminology needs to be explained and clarified. This issue is one of the most challenging aspects of interpretation because Chin-Hakha, like many other languages, lacks a history of clinical diagnosis in the Western sense. The traditional conceptualization of health and illness that are associated with the language includes visible signs and symptoms but associates them with aspects of the body that can be observed without the use of technology. This means, for example, that pain is a significant indication of illness, but the aetiology of the source of the pain is not part of the traditional understanding of disease. It is for this reason that particular symptoms are difficult for Chin-Hakha speakers to associate with anatomical structures or conditions as they are conceptualized in Western medicine. This cultural distance becomes especially apparent in the context of modern medical services in Australia, which are based on the highly developed, diagnostically-based approach to health and illness that has deep roots in Western culture. Chin-Hakha interpreters often need to provide an understanding of concepts that do not exist in the cognitive framework of Chin-Hakha speakers using available terms that originate from a different perceptual structure and that reflect a very different worldview, history, and culture. This lack of fit suggested the need for this study, which was intended to find out what happens in practice and to elucidate the extent to which Chin-Hakha community interpreters explain or paraphrase medical terminology when providing interpreting services in medical settings with a focus on the degree of latitude applied relative to the English source material.

\section{Methodology}

This study used a simulated medical interpreting dialogue in which a bilingual actor performed both patient and doctor roles, while a paraprofessional ChinHakha community interpreter interpreted the medical dialogue consecutively. The actor made clear to the interpreter participants the role he was playing through the manner of delivery. Following the interpretation, the participants were interviewed about their decision-making processes in the rendition of a number of medical terms. They were also asked about any difficulties they 
might have had with some of the medical terminology used and why they decided to interpret the medical terms in the way they did. These interviews were conducted in Chin-Hakha to allow for maximum explanation and discussion.

Six interpreters (two men and four women) who were native Chin-Hakha speakers with English as their second or third language took part in this study. All had completed a Diploma of Interpreting in Melbourne, with Chin-Hakha and English as working languages, and passed the paraprofessional accreditation test of the Australian National Accreditation Authority for Translators and Interpreters (NAATI) ${ }^{\mathrm{ii}}$. These two requirements were to ensure reliable data were obtained: trained paraprofessional Chin-Hakha interpreters were expected to provide better quality interpretation, as opposed to untrained interpreters, who are generally regarded as "reliably unreliable" (Stewart, Cartwright \& Schein 2004, p. 145). There are only 12 paraprofessional Chin-Hakha interpreters residing in Melbourne who fulfil these criteria and six of them agreed to participate in this study. The interpreters who took part in this study are representative of the wider language community of first language Chin-Hakha speakers. All were aged between 23 and 30 with one to five years of experience. As younger members of the community, their English skills were better than those of older ChinHakha speakers, for whom they usually interpreted.

Before the simulated dialogue, the participants were given briefing and simulated patient information in order to contextualise the dialogue. This study assessed lexical strategies employed by Chin-Hakha community interpreters who provide medical interpreting services in Melbourne. The study's aim was to evaluate interpreters' renditions of medical terminology in an interpreting scenario. The medical terms used in the scenario included colonoscopy, digestive tract, gastroenterologist, gastroscopy, heartburn, indigestion, oesophagus, and stomach ulcers.

\subsection{Strategies employed by paraprofessional Chin-Hakha interpreters when interpreting medical terminology}

While the full dialogues contained many examples of equivalence that represented the results of interpreter decision-making, only the rendition of specific medical terminology was of interest and was subsequently analysed.

The term 'heartburn' did not present a challenge for participants in terms of comprehension. Only a low level of explanation or clarification was provided in their renditions: four of the participants gave a one-word rendition, thinlin. The literal back-translation in English of this word is 'liver hot.' This reflects the metaphorical structure of Chin-Hakha as compared to English. Heartburn, which is an easily recognizable condition that does not require clinical confirmation, fits into the traditional conceptualization of both languages. In English, the term 'heart' is used figuratively to identify the general location of the burning sensation. In Chin-Hakha, it is the liver that metaphorically burns.

The interpretation by Participants 4 and 6 include some explanation, in line with meaning-based interpreting, referring to the 'stomach' instead of the 'liver'. In Chin-Hakha, the 'liver' is not the same as the 'stomach'; however, the interpretation of 'stomach burns' is an accurate description and rendition.

\footnotetext{
ii There are no Chin-Hakha interpreters who are accredited at a professional level in Australia.
} 
These two interpreters have taken a wider degree of latitude than the other four, providing the explanation 'burning like a flame' to expand on their interpretation. Their interpretation is in line with the explanation for 'heartburn' that appears in the Chin-Hakha English Dictionary (Bawi-Hu, 2007, p. 610): Rawl rial khawh lo ruang ah pawpi asiloah ttang linhnak ('An unpleasant burning feeling in your stomach or chest caused by indigestion').

Table 1: Renditions for the term 'heartburn'

\begin{tabular}{|l|l|l|}
\hline Participant & Chin-Hakha interpretation & Literal English back-translation \\
\hline P1 & Thinlin & Liver hot \\
\hline P2 & Thinlin & Liver hot \\
\hline P3 & Thinlin & Liver hot \\
\hline P4 & $\begin{array}{l}\text { Paw chunglei meialh bang } \\
\text { in linh }\end{array}$ & $\begin{array}{l}\text { Inside of stomach is hot or burning like } \\
\text { a flame }\end{array}$ \\
\hline P5 & Thinlin & Liver hot \\
\hline P6 & Ka paw chung a lin & My stomach inside burns or is hot \\
\hline
\end{tabular}

The term 'indigestion' was similarly straightforward. Participant 1 described having a meal first, which causes stomach problems and difficulty in digesting. In contrast, Participants 2 and 3 interpreted the term as 'stomach is not strong enough to digest'. Even with lexical dissimilarity, these interpretations make sense in conceptual terms, and render the original meaning faithfully in Chin-Hakha through a meaning-based interpreting approach (see Dam, 2000).

Participants 4 and 5 added an extra word, 'food', in their interpretation. A word $(\mathrm{rawl}=\mathrm{food} / \mathrm{meal})$ and an extra verb $($ rial $=$ digest/grind $)$ were included in Participant 5's rendition. These two participants' renditions are similar, referring to food that is not digested properly. Participant 6's interpretation (My stomach is uncomfortable) is interesting, using the first person 'my' to convey the meaning in Chin-Hakha. It is worth noting that the use of 'my' adheres to recommended professional conduct: interpreters are urged to use the first person, 'I' or 'my', rather than 'he/she' when rendering a client's speech. In other words, they are expected to mimic exactly the standpoint of the speaker of the utterance, rather than convey their third-party standpoint as a participant to the conversation. The remaining phrase, stomach is uncomfortable, is similar to Participant 1's interpretation - 'unhappy' and 'uncomfortable' are similar in meaning in Chin-Hakha.

After consulting with a medical practitioner from a Chin background, a medical glossary in English, and Chin-Hakha dictionaries, it was concluded that each participant's interpretation is both accurate and acceptable. Moore (2004) defines indigestion as "difficulty in digesting food; pain or discomfort caused by this"; consequently, it implies having food (P1, P4 and P5), "grind not right" (P2, P3, P4, and P5) as well as discomfort (P1 and P6). 
Table 2: Renditions for the term 'indigestion'

\begin{tabular}{|l|l|l|}
\hline & Chin-Hakha interpretation & Literal English back-translation \\
\hline P1 & Rawl ei dih in paw nuam lo & After meal stomach unhappy \\
\hline P2 & $\begin{array}{l}\text { Pawpi rial cak lo (Pawpi rial } \\
\text { khawh lo) }\end{array}$ & $\begin{array}{l}\text { Stomach big grind strong not (stomach big } \\
\text { grind unable) }\end{array}$ \\
\hline P3 & Pawpi rial khawh lo & Stomach big grind-able not \\
\hline P4 & Rawlrial ahman lo & Food grind not right \\
\hline P5 & Rawl tha tein a rial kho lo & Food in good way not grind \\
\hline P6 & Ka paw sia a rem lo & My stomach uncomfortable \\
\hline
\end{tabular}

The term 'digestive tract' was more problematic. Here, all participants were only partially correct in their interpretations, as they all failed to describe fully the meaning of 'digestive tract', which includes the stomach, small intestine and large intestine. Participants 3 and 6 were closest to successfully rendering the utterance. The other participants committed omission-type errors where words or terms are left out, as well as false fluency errors, where words that are incorrectly used or not part of the target language are used. Four participants borrowed words from the Burmese language: sinpit (P1) and piahtana $(\mathrm{P} 3, \mathrm{P} 4, \mathrm{P} 5)$.

Table 3: Renditions for the term 'digestive tract'

\begin{tabular}{|l|l|l|}
\hline & Chin-Hakha interpretation & Literal English back-translation \\
\hline P1 & Paw that lo, paw lei sinpit lo & Stomach no good, stomach part not so well \\
\hline P2 & Pawfahnak a ngeimi & Stomach ache/pain suffer that person \\
\hline P3 & $\begin{array}{l}\text { Rawl-eimi a luhnak } \\
\text { lamhrawng pawpi lei piahtana }\end{array}$ & $\begin{array}{l}\text { Where food enters areas/way, and caused } \\
\text { stomach problems }\end{array}$ \\
\hline P4 & Rawlrial khawhlonak piahtana & Food grinding problems/issues \\
\hline P5 & $\begin{array}{l}\text { Rawlrialnak he pehtlai in } \\
\text { piahtana }\end{array}$ & Food grinding part of problems/issues \\
\hline P6 & $\begin{array}{l}\text { Rawleinak a luhnak lam, } \\
\text { pawpi lei in siseh, mah pawl } \\
\text { zawtnak angeimi.... }\end{array}$ & $\begin{array}{l}\text { Where food enters areas/way, that kind of } \\
\text { sickness, illness and disease of stomach }\end{array}$ \\
\hline
\end{tabular}

Sinpit is a Burmese loanword meaning 'fine' or 'well'. Piahtana is also a Burmese loanword that means 'problem' or 'issue'. This term was used by Participants 4 and 5 in discussing stomach ulcers as well and is a direct reflection of the difficulty in expressing medical terms with available lexical items in Chin-Hakha.

'Stomach ulcers' did not require extensive explanations or clarification. Three of the participants (P1, P2, and P6) used the word hma in their interpretations, which is succinct. Hma in Chin-Hakha refers to a sore area outside the body or on the surface of an organ inside the body, which produces

iii Participant's self-correction. 
a poisonous substance. However, some participants' interpretations indicate a lack of understanding of the medical term. For example, Participant 4's interpretation (Pawpi Lei, chungril lei piahtana) and Participant 5's interpretation (Pawpi fak) have no meaning in Chin-Hakha. In fact, the medical term 'stomach ulcers' was distorted in these interpretations (as shown in the literal English back-translation). Likewise, Participant 3's interpretation (Pawpi arsa) makes no sense in Chin-Hakha. He combined two languages: Chin-Hakha (pawpi) and English (ulcer): he retained the English term 'ulcer' but gave it a twist by pronouncing it with a Chin-Hakha accent (arsa). (The literal meaning of arsa is 'cooked chicken'). This represents false fluency (see Anazawa, Ishikawa \& Kiuchi, 2012), wherein the interpreter uses words or phrases that are incorrect/non-existent in a language. The distortion in the interpretation (pawpi arsa) was unnecessary because there is a suitable term in Chin-Hakha to convey the meaning of ulcer ( $h m a)$, which most of the other interpreters used.

Table 4: Renditions for the term 'stomach ulcers'

\begin{tabular}{|l|l|l|l|}
\hline & Chin-Hakha interpretation & Literal English back-translation \\
\hline P1 & Pawpi chung i a hmami & Stomach inside wounds \\
\hline P2 & Pawpi hma & Stomach wound \\
\hline P3 & Pawpi arsa & Stomach ulcer \\
\hline P4 & $\begin{array}{l}\text { Pawpi lei, chungril lei } \\
\text { Piahtana }\end{array}$ & $\begin{array}{l}\text { Stomach way internal part of stomach } \\
\text { problems }\end{array}$ \\
\hline P5 & Pawpi fak & Stomach pain/sore \\
\hline P6 & Pawpi chung i a hmami & Stomach part that's wounded & \\
\hline
\end{tabular}

Interpreting the term 'oesophagus' required a wider degree of latitude because there is no single word in Chin-Hakha that conveys this meaning. The word rawl (meaning 'food') was used in all participants' interpretations to qualify the Chin-Hakha rendered words. For example, in Participant 5's interpretation: Kan Kaa in pawpi tiang rawl le ti akalnak lam ('From our mouth to stomach water and food entrance way/road/street'), the participant used latitude in devising an interpretation (using 'entrance way/road/street' for 'tube') that he thought was the most appropriate explanation in Chin-Hakha in consideration of the receiver/simulated patient. The other participants prioritised a meaning-based interpreting approach in their explanations, partially explaining the 'oesophagus' as 'food entrance tube'. A more complete interpretation in Chin-Hakha would have been hrom le pawpi apehtu rawl kalnak peeng (Lian-Ching, 2014, p. 149). The literal back-translation in English of this phrase is 'throat and large stomach connector food way pipe/tube'.

\footnotetext{
iv Chin pronunciation of the English word 'ulcer'.
} 
Table 5: Renditions for the term 'oesophagus'

\begin{tabular}{|l|l|l|}
\hline & Chin-Hakha interpretation & Literal English back-translation \\
\hline P1 & Rawl a rak tlaknak zawn & Food drop from up to down place/spot/part \\
\hline P2 & Rawl luhnak hri & Food entrance tube/robes \\
\hline P3 & Rawl luhnak peng & Food entrance pipe \\
\hline P4 & $\begin{array}{l}\text { Kan pawpi le rawl an } \\
\text { itonnak }\end{array}$ & $\begin{array}{l}\text { Our stomach and food a place (where) they } \\
\text { meet }\end{array}$ \\
\hline P5 & $\begin{array}{l}\text { Kan kaa in pawpi tiang ti le } \\
\text { rawl kalnak lam/kua }\end{array}$ & $\begin{array}{l}\text { From our mouth to stomach water and food } \\
\text { entrance way/road/street }\end{array}$ \\
\hline P6 & Rawl luhnak lei & Food entrance part \\
\hline
\end{tabular}

In interpreting or explaining specialised medical professional titles such as 'gastroenterologist', Chin-Hakha interpreters require lengthy explanation and clarification, similar to what Scaioli (2000) found among Navajo interpreters. The word 'gastroenterologist' does not appear in Chin-Hakha dictionaries and thus represents a terminological challenge for Chin-Hakha interpreters. However, the participants understood the meaning of 'gastroenterologist' and all were able to convey the meaning of the term. Participant 1's rendition indicates how the explanation and clarification was achieved: Kan Pawchung lei zawtnak zohtu Sibawi/Paraku ('Our stomach internal part disease watcher/viewer doctor'), where one word in English becomes ten words in Chin-Hakha. At the word or semantic level, Participant 2 broke up this medical term into two pieces: 'gastro' (or 'stomach') and '-ist' (which signifies a person who practices or specialises in something); the middle part of 'entero' was omitted and disregarded. Participant 1 also added extra information, zawtnak (which means 'disease', 'sickness' or 'illness').

Table 6: Renditions for the term 'gastroenterologist'

\begin{tabular}{|c|c|c|}
\hline & Chin-Hakha interpretation & Literal English back-translation \\
\hline P1 & $\begin{array}{l}\text { Kan paw lei zawtnak zohtu } \\
\text { siibawi/Paraku }\end{array}$ & $\begin{array}{l}\text { Our stomach internal part disease } \\
\text { watcher/viewer doctor }\end{array}$ \\
\hline P2 & Pawpi lei Paraku & Stomach specialist \\
\hline P3 & Pawpi chunglei zohtu & Stomach watcher or viewer \\
\hline P4 & $\begin{array}{l}\text { Chunglei an zoh tu ding } \\
\text { Sayawin }\end{array}$ & Internal part of body viewer/watcher doctor \\
\hline P5 & $\begin{array}{l}\text { Pawpi chunglei zohtu attukuh } \\
\text { siibawi }\end{array}$ & $\begin{array}{l}\text { Stomach watcher or viewer whom is a } \\
\text { specialist doctor }\end{array}$ \\
\hline P6 & $\begin{array}{l}\text { Pawpi lei ahlei in athiammi } \\
\text { Sibawi }\end{array}$ & $\begin{array}{l}\text { Stomach extra who is expertise whom is } \\
\text { doctor }\end{array}$ \\
\hline
\end{tabular}

The closest equivalent word for 'gastroenterologist' in Chin-Hakha is 'doctor'. However, this particular medical term needed a more concrete explanation. Starting from 'doctor', the participants expanded on the doctor's role, emphasising that this doctor specifically examines the stomach. Thus, the 
participants used a combination of two or three of the following elements, as exemplified by Participant 1's interpretation, which included: (1) a word for a body part, (2) a word for disease, and (3) a word for doctor or medical practitioner.

It is interesting to note that four participants borrowed the Burmese words for 'doctor' or 'specialist medical practitioner' in their interpretations: paraku, sayawin and attukuh (Participants 1, 2, 4 and 5). The Chin-Hakha word for 'doctor' is siibawi, which was used alongside the Burmese word by Participants 1,5 and 6. The use of both the Chin-Hakha and Burmese words for 'doctor' within the same interpretation is, I think, an unconscious strategy used by the participants to emphasise the importance of the word 'doctor' in their interpretations/explanations. Most Chin-Hakha interpreters are also fluent in Burmese, and sometimes use Burmese words in interpretations for elaboration or emphasis. Nevertheless, the pretend-patient in this study is from a rural area in the Chin State and her Burmese would be very limited. Thus, the patient would not have been able to understand Burmese words and the decision by some of the participants to include a Burmese word in their interpretation was undesirable in this case. Chin-Hakha interpreters often borrow foreign words, particularly from Burmese and English, but it is reasonable to argue that loanwords are acceptable only when lexical equivalence is not achievable in rendering medical terminology.

As with the term 'gastroenterologist', 'gastroscopy' requires a lengthy explanation and some medical knowledge. 'Gastroscopy' is a highly technical medical term and all the participants struggled to compose an accurate rendition. However, their renditions do carry the intended meaning in ChinHakha. Patients will understand what gastroscopy is from these interpretations, even considering the relatively low educational background of the hypothetical patient in this study. Three participants retained the English word 'gastroscopy' in their interpretations and gave it a twist by pronouncing it with a Chin-Hakha accent, followed by explanation and clarification. I believe this was not a good decision on the part of the interpreters because the pretend-patient would not have been able to understand the English word.

Table 7: Renditions for the term 'gastroscopy'

\begin{tabular}{|c|c|c|}
\hline & Chin-Hakha interpretation & Literal English back-translation \\
\hline P1 & $\begin{array}{l}\text { Pawlei a zohnak dingmi thil, } \\
\text { achung lei vialte zohkhawhnak }\end{array}$ & $\begin{array}{l}\text { Stomach part an object, thing internal/inside } \\
\text { the whole part that viewable or watchable }\end{array}$ \\
\hline P2 & $\begin{array}{l}\text { Gastroscopy timi cu ka chim cia } \\
\text { bang, oesophagus timi kan rawl } \\
\text { luhnak lei in an zoh }\end{array}$ & $\begin{array}{l}\text { Gastroscopy is as I said before, from } \\
\text { oesophagus our intake food entrance way is } \\
\text { looked by it }\end{array}$ \\
\hline P3 & $\begin{array}{l}\text { Gastroscopy timi cu na rawl } \\
\text { luhnak in na paw tiang an } \\
\text { zohnak }\end{array}$ & $\begin{array}{l}\text { Gastroscopy is from your food enter space } \\
\text { to your stomach look and viewer/ things (an } \\
\text { object) }\end{array}$ \\
\hline P4 & $\begin{array}{l}\text { Gastroscopy timi cu chungril lei } \\
\text { kha kan kaa lei inkhan kan } \\
\text { chunglei kha zeibantuk dah um } \\
\text { timi kha zohnak ah hmanmi } \\
\text { camera bantuk asi }\end{array}$ & $\begin{array}{l}\text { Gastroscopy is intestine part there from our } \\
\text { mouth to our internal/inside of our body, } \\
\text { what is it and which caused problems there } \\
\text { checker, tester or like a camera }\end{array}$ \\
\hline P5 & Na pawpi chunglei va zohnak & Your stomach inside examiner/checker \\
\hline P6 & Na kalei in rawnmi thil khi asi ko & $\begin{array}{l}\text { Your mouth from put it an object/thing is } \\
\text { called }\end{array}$ \\
\hline
\end{tabular}


Participant 4 gave the most accurate description by resorting to a lengthy explanation: Gastroscopy timi cu chungril lei kha kan kaa lei inkhan kan chunglei kha zeibantuk dah um timi kha zohnak ah hmanmi camera bantuk asi ('Gastroscopy is intestine part there from our mouth to our internal/inside of our body, what is it and which caused problems there checker, tester or like a camera'). Participant 4 constructed his/her interpretation using several elements: (1) a reference to body parts (intestine, mouth, inside our body); (2) a reference to problems with the body part (what it is that caused problems); and (3) a reference to an object used in gastroscopy (checker, tester, camera).

The medical term 'colonoscopy', as seen from the participants' interpretations, required the same lengthy explanations and clarifications as 'gastroscopy'. All the Chin-Hakha interpreters came up with quite long and dense literal passages of explanation and clarification. Participants managed to convey the meaning of the term through a meaning-based rather than formbased approach (Dam, 2000). Their interpretations are all acceptable renditions in terms of meaning transfer (note that Participant 1 did not interpret the term - an omission, which is a common but unfortunate occurrence during interpreting). As with 'gastroscopy', the participants constructed their interpretation using several elements: (1) a reference to a body part (anal way, bottom part, rectum); (2) reference to problems with the body part (wrong inside); and (3) reference to an object used in colonoscopy (checker, viewer, examiner).

Table 8: Renditions for the term 'colonoscopy'

\begin{tabular}{|c|c|c|}
\hline & Chin-Hakha interpretation & Literal English back-translation \\
\hline $\mathrm{P} 1$ & Omitted & No interpretation \\
\hline P2 & $\begin{array}{l}\text { Colonoscopy timi cu kan ek ek } \\
\text { nak kan ril lei an zoh lai }\end{array}$ & $\begin{array}{l}\text { Colonoscopy is our excrement/anal way and } \\
\text { our colon part will be checking }\end{array}$ \\
\hline P3 & $\begin{array}{l}\text { Colonoscopy cu na tanglei na } \\
\text { ek eknak, a chuahnak lei le na } \\
\text { rilpi a zoh lai }\end{array}$ & $\begin{array}{l}\text { Colonscopy is your bottom part and your poo } \\
\text { way out from to your colon be checked }\end{array}$ \\
\hline P4 & $\begin{array}{l}\text { Colonoscopy timi cu kan tawlei } \\
\text { in khan kan chungril kan pawpi } \\
\text { te hna zeidah a cang ti zohnak } \\
\text { a si }\end{array}$ & $\begin{array}{l}\text { Colonoscopy is our anal part from our } \\
\text { intestine internal part, what is wrong } \\
\text { checker/examiner }\end{array}$ \\
\hline P5 & Tawlei in zohnak & From anal way checker/viewer \\
\hline P6 & $\begin{array}{l}\text { A tanglei na ta-fih in luhtermi } \\
\text { khi a si }\end{array}$ & $\begin{array}{l}\text { The bottom part, your anal/rectum from } \\
\text { put/insert it }\end{array}$ \\
\hline
\end{tabular}

\section{Discussion}

Despite the lack of equivalent medical terminology in Chin-Hakha for the common medical terms required in this scenario, the participants produced clear and acceptable renditions through exercising latitude. They are meaningbased interpreters (see Dam, 2000), able to convey the spirit and connotations of the original message. They acted as 'clarifiers' (see Dysart-Gale, 2007), striving for meaning rather than word-for-word interpretation. Interestingly, the Chin-Hakha interpreters in this study took a more structured approach to interpreting medical terms. This approach is summarised in Table 9 below.

The simplest interpreting strategy for describing a part of the body involves describing the function of the body part. For example, the oesophagus is described as 'food drop from up to down'. However, in the Translation \& Interpreting Vol 9 No 2 (2017) 
context of medical interpreting, where the patient has come in for diagnosis of a problem, some interpreters include a symptom (ache, pain, disease) in the description of the body part, which supports their clarifying role. The interpreting strategy for medical conditions is similar to the strategy for parts of the body: it consists of rendering a word for the body part (stomach, liver, or colon), which may be followed by a cause (food, meal), and/or a symptom (burns, hot, pain, unhappy, not grind). Sometimes, explicit mention of the body part is omitted since it is already implied in the cause - for example, 'stomach' is implied in the mention of 'food' as the cause for the symptom 'not grind'. The interpreting strategy for medical procedures is also twofold: first, a word for the body part (stomach, stomach inside, anal part) is rendered, followed by a verb (look, examine, and check). In the case of interpreting terms for specialist medical practitioners, the word 'doctor' is always included, then a word for the body part being examined (stomach, colon), and then the job the doctor does (examiner, watcher, viewer).

Table 9: Typology of interpreting strategies

\begin{tabular}{|c|c|c|}
\hline $\begin{array}{l}\text { Type of } \\
\text { medical } \\
\text { term }\end{array}$ & $\begin{array}{l}\text { Chin-Hakha interpreters' } \\
\text { interpreting strategy }\end{array}$ & Examples from data \\
\hline $\begin{array}{l}\text { Part of } \\
\text { anatomy }\end{array}$ & $\begin{array}{l}\text { Description of function of } \\
\text { body part }\end{array}$ & $\begin{array}{l}\text { Oesophagus }=\text { food drop from up to } \\
\text { down } \\
\text { Oesophagus }=\text { food entrance part }\end{array}$ \\
\hline $\begin{array}{l}\text { Part of } \\
\text { anatomy }\end{array}$ & Body part + symptom & Digestive tract $=$ stomach + ache $/$ pain \\
\hline $\begin{array}{l}\text { Part of } \\
\text { anatomy }\end{array}$ & $\begin{array}{l}\text { Body part }+ \text { description of } \\
\text { function body part }+ \\
\text { symptom }\end{array}$ & $\begin{array}{l}\text { Digestive tract }=\text { stomach (implied by the } \\
\text { word 'food') }+ \text { enter }+ \text { disease suffer }\end{array}$ \\
\hline $\begin{array}{l}\text { Medical } \\
\text { condition }\end{array}$ & Body part + symptom & $\begin{array}{l}\text { Indigestion = stomach }+ \text { uncomfortable } \\
\text { Heartburn = stomach }+ \text { burns } \\
\text { Heartburn = liver }+ \text { hot } \\
\text { Stomach ulcer }=\text { large intestine }+ \text { wound } \\
\text { Stomach ulcer = colon }+ \text { pain }\end{array}$ \\
\hline $\begin{array}{l}\text { Medical } \\
\text { condition }\end{array}$ & $\begin{array}{l}\text { Body part }+ \text { cause }+ \\
\text { symptom }\end{array}$ & $\begin{array}{l}\text { Indigestion = stomach }+ \text { meal }+ \text { unhappy } \\
\text { Indigestion = stomach }(\text { implied })+\text { food }+ \\
\text { not grind }\end{array}$ \\
\hline $\begin{array}{l}\text { Medical } \\
\text { procedure }\end{array}$ & Body part + verb & $\begin{array}{l}\text { Gastroscopy }=\text { stomach }+ \text { look } \\
\text { Gastroscopy }=\text { stomach inside }+ \\
\text { examiner } \\
\text { Colonoscopy }=\text { anal part }+ \text { checker }\end{array}$ \\
\hline $\begin{array}{l}\text { Medical } \\
\text { practitioner }\end{array}$ & $\begin{array}{l}\text { Body part }+ \text { job } \\
\text { description + 'doctor' }\end{array}$ & $\begin{array}{l}\text { Gastroenterologist }=\text { stomach }+ \text { watcher } \\
+ \text { doctor } \\
\text { Gastroenterologist }=\text { colon }+ \text { viewer }+ \\
\text { doctor }\end{array}$ \\
\hline
\end{tabular}

It is unlikely that any of the participants explicitly or consciously employed these strategies while interpreting. Instead, it is probably the case that that these constructions form an implicit part of their linguistic skills and medical knowledge and reflect the cognitive framework of the language as well as its conventional usages. It was also the case that the participants used as much latitude as they felt necessary for the situation and included long and dense explanatory passages. This reflects a meaning-based interpretation resting on an expanded and controversial understanding of the role of 
interpreters as clarifiers (Dysart-Gale, 2007). However, interpreting medical terminology in this manner requires interpreters to incorporate a certain number of meaning elements in their explanations/clarifications, and the incorporation of these elements is carried out in observably patterned ways. As such, medical interpreting can be thought of as structured and purposeful (a meaning-based approach that is mixed with a form-based approach), which allows for highly successful meaning transfer.

\section{Conclusion}

The findings of this study indicate that the paraprofessional Chin-Hakha interpreters tend to rely on a strategy of paraphrasing medical terminology in English to overcome the fact that the two languages have very different sets of vocabularies available to discuss medical and health issues. In many cases, a lengthy description of the meaning of a medical term is required to convey its sense, and sometimes interpreters even resort to the use of words from Burmese, which is understood by many Chin-Hakha speakers. While the findings of this study are specific to issues that may arise in interpreting between Chin-Hakha and English, the type of problems in equivalence outlined occur in many other languages that are used in Australia. As interpreting provides significant support for patients in the healthcare system, it is important to have a better understanding of the strategies interpreters use to ensure equivalence in a way that allows their clients to understand the health issues of concern. Since every language has its own unique features, it is likely that interpreter strategies may differ from one language to another, and some may be more suitable than others for specific languages or specific contexts. Nonetheless, investigation of these strategies can enrich our knowledge of the interpreting process and permit better support for clients with diverse language needs, especially in the case of less widely spoken languages which have little literature to serve as the basis for practice.

\section{Acknowledgements}

The author gratefully acknowledges the support of Associate Professor Rebecca Fanny, Dr. Caroline Norma and Dr. Iris E. Dumenden in the preparation of this article.

\section{References}

Angelelli, C.V. (2004). Medical interpreting and cross-cultural communication. Cambridge: Cambridge University Press.

Anazawa, R., Ishikawa, H., \& Kiuchi, T. (2012). The accuracy of medical interpretations: A pilot study of errors in Japanese-English interpreters during a simulated medical scenario. Translation \& Interpreting: The International Journal of Translation \& Interpreting Research, 4 (1), 1-20.

Bawi-Hu. (2007). English-Chin/Myanmar Dictionary. Yangon, Myanmar: Gantgawo Offset.

Dam, H.V. (2000). On the option between form-based and meaning-based interpreting: The effect of source text difficulty on lexical target text form in simultaneous interpreting. The Translator, 4 (1), 49-68. 
Dysart-Gale, D. (2007). Clinicians and medical interpreters: Negotiating culturally appropriate care for patients with limited English ability. Family and Community Health, 30 (3), 237-246.

Hatim, B., \& Mason, I. (1990). Discourse and the translator. London: Routledge.

Hsieh, E. (2006). Conflict in how interpreters manage their roles in provider patient in reactions. Social Science \& Medicine, 62 (3), 721-730.

Larson, M. L. (1998). Meaning-based translation: A guide to cross-language equivalence. Lanham, MD: University Press of America.

Lian-Ching, S. B. Z. (2014). Holhlettu Kutken: English -Chin [Hakha] Dictionary. Delhi, India: Indian Society for Promoting Christian Knowledge.

McCabe, M., Morgan, F., Smith, M., Yazzie, E., Spencer, A., Curley, H., Begay, R., Gohdes, D. (2003). Challenges in interpreting diabetes concepts in the Navajo language. Diabetes Care, 26 (6), 1913-1914.

Morris, R. (1995). The moral dilemmas of court interpreting. The Translator, 1 (1), 25-46.

Moore, B. (2004). The Australian concise Oxford dictionary. Melbourne: Oxford University Press.

Munday, J. (2012). Introducing translation studies: Theories and applications. London: Routledge.

Newmark, P. (1988). A textbook of translation (Vol. 1, p. 988). New York: Prentice hall.

Napier, J., McKee, R., and Goswell, D. (2010). Sign language interpreting: Theory \& practice in Australia and New Zealand (2nd Ed.) Sydney: The Federation Press.

Orlando, M. (2010). Interpreting eloquence: when words matter as much as ideas. The AALITRA Review, 1, 52-60.

Pöchhacker, F., \& Shlesinger, M. (2007). The interpreting studies reader. London and New York: Routledge.

Roger, K. L. (1999). Medical interpreting: Obstacles can be challenges. RID Views, 16 (9).

Stewart, D., Cartwright, B. and Schein, J. (2004). Sign language interpreting: Its Art and Science. 1st ed. Boston: Pearson.

Scaioli, I. (2000). Medicine, culture and power: Interpreting for Navajo people in medical settings. Retrieved from http://lingue2.lingue.unibo.it/didattica/ inglese/rudvin/interpreting $\% 20$ for $\% 20$ navajo $\% 20$ people $\% 20$ in $\% 20$ medical $\%$ 20settings $\% 20-\% 20$ scaioli.pdf $\% 20$ 